\title{
Assessing Interdisciplinary Research in the Social Sciences: Are we on the right track?
}

Joshua Eykens

ECOOM - University of Antwerp

Middelheimlaan 1

2020 Antwerp, Belgium

E-mail: joshua.eykens@uantwerpen.be

ORCID: https://orcid.org/0000-0002-1680-0112

\section{ABSTRACT}

In this chapter we first discuss how interdisciplinarity is perceived in research policy making and in applied bibliometric research. We put forward a processual view on disciplines and interdisciplinarity in the social sciences which emphasizes the changing nature of disciplines and the heterogeneity of individual fields. This view challenges the current status quo in the development of bibliometric indicators as well as qualitative research assessment exercises. We propose a stance in which the focus is shifted to the changing dynamics of the social sciences in order to develop a better understanding of interdisciplinarity. We point out that the cognitive and socio-cultural diversity of disciplines makes it difficult to transfer current disciplinary peer review practices to the evaluation of interdisciplinarity. We reiterate seven principles proposed by Klein which might guide more appropriate evaluation practices suitable for the assessment of interdisciplinarity in the social sciences.

KEYWORDS: research evaluation, peer review, bibliometric indicators, interdisciplinarity, discipline

\section{INTRODUCTION}

The new adage in research policy making seems to become: "Interdisciplinarity is here to solve the most complex societal problems". Assessment of scholars incorporates this idea and different indicators and assessment procedures are being developed to be able to better account for the "interdisciplinarity" of research output, research and/or teams. Large research funding organizations, like the European Commission and the European Research Council (Allmendinger, 2015), the National Science Foundation (NSF) in the USA, and the National Natural Science Foundation of China (NSFC) share this perspective and give high priority to interdisciplinarity, for example by developing specific financing opportunities for interdisciplinary research (IDR).

The reasoning goes that interdisciplinarity should be encouraged because it is bound to entail innovative and concrete, problem-oriented research. Interdisciplinary research also allows the boundaries of the various disciplines to be crossed. These assumptions are reflected in the definition of interdisciplinary research put forward by the National 
Academies (2005) that is common in policy documents, bibliometrics and research evaluation studies:

"Interdisciplinary research is a mode of research by teams or individuals that integrates information, data, techniques, tools, perspectives, concepts, and/or theories from two or more disciplines or bodies of specialized knowledge to advance fundamental understanding or to solve problems whose solutions are beyond the scope of a single discipline or area of research practice."

Fundamental breakthroughs are expected to emerge from interdisciplinary research; by means of the integration of knowledge from separate disciplines, one can face so-called "grand challenges" for which the solutions lie outside the boundaries of a single discipline. It is often assumed that integration cannot arise within the individual disciplines as such: new solutions and insights related to pertinent societal challenges are the result of the integration of information, data, techniques, tools, perspectives and theories or concepts from the different disciplines.

As Bonnie Wolff-Boenisch, head of research affairs at Science Europe stated, however, "interdisciplinarity is not new, but [in Europe] it has gained increasing traction in the context of the global transformation of societies, the SDG's, and the 'Mission-oriented research' concept of the European Commission" (Science Europe;, 2019). Bibliometricians and science policy makers alike, however, are working hard on the development of new indicators to measure different facets of IDR (Wang \& Schneider, 2019).

In the following, we will first highlight the two main paths which are being explored in this race for indicators. We discuss the suitability of the approaches in light of the changing nature of disciplines and the social sciences as a whole. In a second part we discuss research into the qualitative strand of research assessment (e.g. peer review) in the context of IDR. In a third section we discuss seven principles put forward by Klein (2008) to guide interdisciplinary research assessment and peer review.

\section{INDICATORS OF INTERDICIPLINARITY IN THE SOCIAL SCIENCES}

When proposing bibliometric indicators for the identification and measurement of IDR, the aforementioned definition of the National Academies is quoted almost by default (cf. supra). Strong emphasis is hereby placed on the need for a proxy that captures the 'integrative component' of IDR. Knowledge integration, it is argued, takes place when combinations of discipline-specific information arise. Those combinations then ensure that the boundaries of the 'disciplinary silos' are transcended. Indicators of interdisciplinarity, and there are quite a few already, therefore take disciplines as a starting point.

Certain bibliographic units (e.g. documents, authors, departments) are categorized ex-ante on, for example, the basis of a discipline code list or the organizational affiliation of the authors is considered. Subsequently, based on those units, it is calculated whether - and to what extent - the integration of information from the various disciplinary units takes place 
(Abramo, D'Angelo, \& Di Costa, 2012; Abramo, D'Angelo, \& Zhang, 2018; Schummer, 2004). Next we will discuss several examples of indicators which are used in research assessment exercises when IDR is concerned.

\subsection{INDICATORS ON THE LEVEL OF RESEARCH OUTPUT}

At the level of individual publications or journals indicators have been proposed that take into account the degree to which work from other fields is cited (Porter \& Rafols, 2009). For this purpose the references in the bibliography of a publication are classified on the basis of a predetermined discipline classification scheme. Subsequently, measures of diversity, such as the Rao-Stirling diversity (Porter \& Rafols, 2009), lead to indicators of interdisciplinarity. Such measures have been applied by the ERC in its "comparative scientometric assessment" of the results of the ERC funded projects (Macaluso, Pollitt, Gunashekar, \& Larivière, 2015). However, research into the consistency of the results emerging from the reference-based indicators points to fundamental inconsistencies (Wang \& Schneider, 2019). The complexity and versatility of interdisciplinarity is cited as a possible explanation for divergence of different citation-based indicators.

Text and topic analysis is also used to develop indicators for IDR. The same premise also holds for this research strand: integration of discipline-specific information, now in the form of textual data, from two or more disciplines equals interdisciplinarity. The text-based indicators have received less attention in the literature to date, but show significant similarities with the citation and reference approaches. Text-based approaches are also used for indicators of IDR with the authors.

\subsection{INDICATORS BASED ON ORGANIZATIONAL AFFILIATION}

An indicator used at the NSF to capture IDR is based on the identification of co-funding arrangements. The rationale behind this indicator is the following: if different directorates (which are discipline-based) fund a single award, than it can be concluded that we have to do with IDR. We should thus be able to identify and subsequently measure IDR by calculating the percentage of awards contributed by each directorate.

Nichols (2014) developed a different indicator which is now also being used at the NSF (USA). Nichols works with disciplinary topic bins. Topics are extracted from project proposals using text mining (LDA - Latent Dirichlet Allocation) and assigned to disciplinary categories. As an indicator for the interdisciplinarity of a document, the number of disciplines that are linked to the topics is counted. Then a diversity index is calculated to consider aspects such as variety and balance of different disciplines contributing.

Evans (2016) developed a similar corpora-based approach. Evans uses the corpus (the raw text from publications) for each disciplinary category in the Web of Science Subject Categories. The corpora of the authors are also classified, and on the basis of similarity scores it is then calculated how similar or different the corpus of the individual researcher is 
compared to the disciplinary corpora. The IDR indicator for an author then starts from those similarity scores between the author's corpus and that of the four closest disciplines.

Gowanlock and Gazan (2013) take a slightly different approach, although, like Evans, they also propose an indicator at the level of the individual authors. To this end, they work with cluster membership of the publications of authors active in astrobiology. On the basis of titles and abstracts, a cognitive map (with the help of text clustering) of the publications is first drawn up. As a result of this clustering, the authors find a number of prominent subdomains. The interdisciplinarity of individual researchers is then calculated on the basis of the number of publications that an author has in the different subdomains, as shown by the clustering; "[A]n author that has publications in many clusters indicates that they are engaged in interdisciplinary research, or perhaps that they are not, but should be." (Gowanlock and Gazan, 2013, p. 158).

\subsection{PROCESSES OF GROWTH AND CHANGE IN DISCIPLINARY STRUCTURE}

The aforementioned approaches, both on the basis of references and on the basis of textual data, place a strong emphasis on knowledge integration as continuous (unique) knowledge flows - in the form of static relationships between different units and their diversity. These methods are very popular and indeed make it possible to estimate to what extent a researcher (or a publication) uses information from different fields in her research at a certain point in time. However, these indicators developed for evaluating IDR take little account of the changing nature and dynamics inherent in scientific research. Scientific fields in the social sciences, as discussed by Bonacorssi (2021, this volume) in this volume, are constantly in flux, and may be more multidisciplinary at a certain point than later in time. The intensity of the relationships that specialisms have with other fields can also vary greatly over time (van den Besselaar, 2019; van den Besselaar \& Heimeriks, 2006; van den Besselaar \& Leydesdorff, 1996).

van den Besselaar and Heimeriks (2001) and van den Besselaar (2019) therefore propose an alternative perspective, drawing attention to patterns of change within the scientific system. According to van den Besselaar (2019), our bibliometric knowledge of interdisciplinarity and how it evolves over time is still too limited to develop adequate indicators. He proposes that we should first approach interdisciplinarity as one of the many components of the continuous processes of change of scientific disciplines. The changing position of journals in the journal landscape is central to van den Besselaar's work. The author cites an important argument for this, one that has also been raised several times in other studies (Abbott, 2001; Jacobs, 2013; Stichweh, 1992): interdisciplinarity is not a characteristic, but a phase in which disciplines can find themselves at a certain point in time. 


\subsection{A DYNAMIC PERSPECTIVE: PROCESSES OF CHANGE IN THE DISCIPLINARY STRUCTURE AND THE ROLE OF INTERDISCIPLINARITY}

Practically all of the disciplines that are now considered as being established units of science had an interdisciplinary start, and may later play a role in the establishment of interdisciplines. Knowledge continuously flows from one discipline to another (see e.g. Jacobs, 2013, chapter 6); the integration in terms of referring to work from other fields is therefore not very special or unique. Scientific specialties are, to a greater or lesser extent, constantly involved in interdisciplinarity. The stabilization of integration processes in the form of new interdisciplinary fields, is the kind of sustainable interdisciplinary integration we want to understand.

For example, sociology, as proposed by one of its founders (August Comte) at the beginning of the 19th century, was based on biological ideas. A number of key concepts that Comte used for his sociological theories came directly from biology, and "his idea of diagnosis followed a medical model" (Heilbron, 1990, p. 262). Harvey Graff (2015) discusses a more recent example with the emergence of communication sciences, a now established field of research that arose from cross-pollination of insights from sociology, political science, psychology, etc. (Graff, 2015, pp. 55-56; Leydesdorff \& Probst, 2009).

According to this view, interdisciplinarity is better understood in terms of developmental phases, a temporary stage through which parts of the scientific system move at a specific point in time, be it as a new interdisciplinary field or as a catalyst in the emergence of a new domain. Over time, a new scientific community can flourish from interdisciplinarity, which may stabilize around a number of problems and develop into a 'normal' disciplinary constellation (Jacobs, 2013; Light \& Adams, 2017; van den Besselaar, 2019).

The focus is thus shifted to dynamics - changes in the science landscape - instead of static representations of integration calculated on the basis of ex-ante classifications, which we mostly fall back on today in bibliometrics. According to van den Besselaar (2019), when we shift attention to processes, we will be able to observe other changes in addition to interdisciplinarity and specialization; the emergence of new fields, the growth and decline or differentiation (disciplines that split into sub-specialisms), integration of specialisms, divergence or convergence, and the extinction of certain domains.

Van den Besselaar does not reject the central idea of integration. Integration is indeed an essential characteristic of interdisciplinarity, but the use of knowledge from other fields (as measured by the diversity of reference lists) actually reflects only to a limited extent whether knowledge is effectively integrated in an innovative way and where that then leads. This is a common criticism also cited by bibliometricians and is based on the fact that a researcher, journal or publication cites sources from two or more other disciplines, but that this does not necessarily mean that this is an (more or less) interdisciplinary journal or publication. 
Attention to process aspects of knowledge integration can provide insight into those uncertainties. In this sense, integration of knowledge from different disciplines is part of the development dynamics of scientific fields. A field integrates knowledge from two or more domains and therefore (to a certain extent) also resembles the fields it integrates. To gain insight into this, van den Besselaar analyzes the citation environment and the position of journals. The author starts from a disciplinary core journal for which he determines the citation environment. He then applies a factor analysis. The factors consist of the journals that exhibit similar citation behavior. Journals with the same citation behavior will therefore together form one factor (van den Besselaar, 2019, p. 3).

\section{PEER REVIEW AND THE QUALITATIVE ASSESSMENT OF INTERDISCIPLINARITY IN THE SOCIAL SCIENCES}

As we have seen, indicators of IDR are 'booming'. Studies of the qualitative evaluation of IDR however, are less numerous. In recent years there has been a slight increase in the number of articles and chapters that look into the social and cognitive dynamics present in (peer review) panels tasked with evaluating IDR research proposals. The existing body of literature on this topic identifies 3 central caveats which should be kept in mind when designing qualitative assessment procedures for interdisciplinary research in the social sciences. (i) The cognitive characteristics which are valued in research communities are different across social science disciplines and (ii) the socio-structural characteristics of social science disciplines differ. It follows that (iii) interdisciplinary endeavors yield unique configurations which require tailor made evaluation procedures. In the following we will briefly clarify each of these caveats and point toward literature relevant for the context of the social sciences.

\subsection{THE COGNITIVE CHARACTERISTICS WHICH ARE VALUED IN RESEARCH ARE DIFFERENT ACROSS SOCIAL SCIENCE DISCIPLINES}

Not all disciplines have the same standards to evaluate research, which makes it difficult to develop a common yardstick for evaluating (interdisciplinary) research. Guetzkow, Lamont, and Mallard (2004) for example, point toward one of the main criteria put forward when reviewers assess research quality: originality. The authors study the importance of originality in the context of peer-review panels from five multidisciplinary fellowship competitions in the US. Relying on interviews with panelists, the authors study how originality is conceived and defined across disciplines. Diversity is found in the ways panelists from the social sciences and the humanities define originality. According to their results, humanists privilege 'originality in approach', whereas social scientists mention originality in terms of method (Guetzkow et al., 2004, p. 190).

Again from the perspective of disciplines, well established methods are often in place. As pointed out by Bonaccorsi (2021, this volume), however, even within one discipline (e.g. sociology), different epistemic communities exist which prefer their own set of methods. While this is often common knowledge for peers from that disciplinary community, we 
cannot expect this to be the case in the context of interdisciplinary collaboration. In many cases of IDR, no established methodological framework is in place (see: Bammer, 2016). It is often devised on the go, or it even is the very essence of the research project in the first place.

These are two simple yet important examples one should keep in mind when bringing together or heading a panel of experts tasked with evaluating interdisciplinary proposals or research outcomes.

\subsection{THE SOCIO-STRUCTURAL CHARACTERISTICS OF SOCIAL SCIENCE DISCIPLINES DIFFER}

The process of evaluation has shown to be deeply interactional and social (Lamont, 2009; Lamont \& Guetzkow, 2016). Lamont and colleagues have conducted a series of in depth studies on the 'informal' structure of multidisciplinary panels in the social sciences and humanities in the US. They show that members from different disciplines have their own ideas of what excellence means and how it should be assessed (cf. the 'cognitive' aspect of originality in research as discussed above). These ideas of excellence, though, are often very implicitly present. In addition, it is found that personal preferences of reviewers play an important role too.

The more formal communicative structure differs across social science disciplines. Bibliometric studies of the social sciences have pointed out that the members of some disciplines prefer to communicate their findings in book format, while in other fields it might be more common to publish journal articles (Kulczycki et al., 2018). The rate with which publications appear differs between the fields as well. Additionally, citation practices vary greatly between different social science disciplines and even sub-disciplines (Larivière, Archambault, Gingras, \& Vignola-Gagné, 2006; Nederhof, 2006). Using an uniform set of indicators within a peer review context might therefore be a bad idea. Especially in the context of interdisciplinary research proposals, it is advisable to take into account these variabilities.

\subsection{INTERDISCIPLINARY ENDEAVORS YIELD UNIQUE COLLABORATION CONFIGURATIONS}

Interdisciplinary research or collaborations are always unique in that attempts are made to find new combinations, or integrate knowledge or techniques and methods so that researchers are able to counter specific societal or scientific problems. Whereas it has been shown that some disciplines are less resistant for their peers to perform interdisciplinary research (see for example: Porter \& Rossini, 1985), researchers from some social science disciplines, e.g. economics, have been shown to be more insular. Contrary to what is commonly held for true, the research conducted by Porter and Rossini (1985) suggests that reviewers typically rarely criticize cross-disciplinary features of proposals. While it is shown 
that researchers prefer work belonging to their own specialty, the aspect of interdisciplinarity or cross-disciplinarity of research proposals is celebrated as a quality.

In addition, when the knowledge or techniques which are combined originate from disciplines which are cognitively more similar to each other, the efforts that need to be made to foster integration can be less problematic. The transfer of epistemological premises and vocabularies is more straightforward when approaches from two cognitively proximate social science disciplines (e.g. social geography and sociology) are combined than when this is the case for two more distant fields (social geography and health sciences). This cognitive aspect which should be kept in mind is also transferable to the socio-structural. Referring to the latter example in which knowledge from social geography is integrated with insights from medical fields (say, epidemiology) it should be kept in mind that completely different publication practices and evaluation criteria are prevalent in both fields. Every interdisciplinary endeavor thus consists of a unique configuration which requires tailor made evaluative procedures.

\section{SEVEN EVALUATION PRINCIPLES FOR ASSESSING IDR IN THE SOCIAL SCIENCES (Klein, 2008)}

To tackle the difficulties which arise in an interdisciplinary research assessment context, seven evaluation principles are proposed by Klein (2008) in her review on the subject. These principles are a bundling of many years of experience with inter- and transdisciplinary research studies and policy making on the part of Klein, but also on part of research management and policy systems currently in place which can be regarded as good practices. Here we recapitulate these seven principles in the context of IDR in the social sciences, and briefly discuss each one. For a detailed discussion of these principles, we refer the reader to the original article by Klein (2008). While every project proposal or research outcome is indeed unique, these seven generic principles can serve an important function when designing evaluation or research assessment procedures for the social sciences.

(1) Variability of goals:

To begin with, not all fields or disciplines in the social sciences harness the same goals. It follows that the individual researchers from these different disciplines will behave differently. Whereas scholars active in more traditional disciplines might have the ambition to create new knowledge about a topic central to their field, researchers from subfields like feminist studies or area studies might have as their main ambition to empower certain groups of people. The same holds true for interdisciplinary research projects. For some, "the production of new and broad knowledge of a particular phenomenon" is important, and for others "the development of technical equipment or products" is the main goal (Klein, 2008). 
(2) Variability of criteria and indicators

The previous principle "drives the variability of criteria and indicators" (Klein, 2008). More traditional indicators, such as the number of publications or citations, for example, are not equally applicable to all disciplines in the same style. When it comes to communicating research, some social science disciplines or specialties value publications in journals more, while other value books as outputs. The same goes for interdisciplinary research. While some projects might be concerned with societal changes, others will be directed towards the development of new scientific methods or techniques to approach a research problem. It goes without saying that these socio-structural differences as well as the differences in perceived goals should be taken seriously by panel members when assessing project proposals and the submitters thereof. Societal impact, for example, should not be assessed with bibliometric indicators only.

\section{(3) Leveraging integration}

Integration is considered to be central to interdisciplinarity. It is therefore crucial to take into account the degree to which initiatives are taken to accomplish or 'leverage' this goal. Klein cites the organization of structural support to allow for integration, like opportunities for communication (meetings among researchers), the development of a common vocabulary, etc. A set of guiding questions has been developed by Klein to take stock off this aspect (see: Klein, 2004)

(4) Interactions of social and cognitive factors in collaboration Interdisciplinary research, like all research, is a social process. Leveraging 'intellectual integration' (the previous principle) is a social endeavor and, according to Klein and others, communication and negotiation 'lie at the heart' of this endeavor. To assess these complex social and cognitive factors, a guide has been provided for in the context of evaluating and studying projects in European research institutes (Bergmann et al., 2005).

(5) Management, leadership, and coaching Here again emphasis is placed on "how well the organizational structure fosters communication". Leadership is an important aspect in this regard, and should thus be taken in consideration when an interdisciplinary research project entails complex collaborations among researchers from different (and disparate) disciplines.

(6) Iteration and transparency in a comprehensive system

According to Klein, a strictly linear evaluation model is not appropriate for the assessment of interdisciplinary research. IDR in many cases develops in different phases and reiterates over these phases. In an early phase, principles 4 and 5 might be very important and thus deserve more attention when intermittent assessments 
are carried out. In a later stage, when an IDR project comes to an end, indicators for research output or impact might become more important. Transparency ensures that evaluators and those who are evaluated are aware of the criteria which are being used at which stage. Ideally, Klein suggests, both evaluators and those who are evaluated get involved when defining appropriate indicators for their goals.

\section{(7) Effectiveness and impact}

The principle of effectiveness and impact returns to the first two principles. The impact of IDR is often "diffused, delayed in time, and dispersed across different areas of study and patterns of citation practice" (Boix-Mansilla, 2006). It is thus required for the assessment of IDR to think through and ideally take into account possible but unpredictable long term impacts.

Most of these principles require an active conversation among those who submit proposals and are conducting interdisciplinary research, and those who evaluate IDR. Appropriate evaluation, Klein states, is not given but made: "It evolves through a dialogue of conventional and expanded indicators of quality". As we have discussed earlier, this is the case because 'peers' in the traditional sense are largely lacking in the case of interdisciplinarity. As such, "there is no consensus on the legitimate sources and types of control over it" (Katri Huutoniemi \& Rafols, 2017). A co-creation model of evaluation procedures much like the one described by Laudel (2006), discussed in the next section and guided by the principles listed above might lead to more appropriate research assessment practices for IDR.

\section{DISCUSSION}

Disciplines are important (if not, the most important) structuring components in modern academia in that sense that they serve as a cognitive address - with their curricular structures in the educational system (Stichweh, 1992) and their organizing structures for knowledge communication amongst its members, they define the boundaries with other disciplines by putting forward expectations with regard to what is expected from its (new) members (i.e. what is the required knowledge for students to be allowed to join the ranks of the discipline, what are the appropriate methods to be used, what are the questions which need to be addressed, and what are the topics to be studied).

The latter is done by the gatekeepers of the discipline (Gieryn, 1999; Lamont, 2009). These gatekeepers are teachers and researchers who are located at review boards of evaluation panels which decide upon funding, the panel members or organizational committee members of conferences, reviewers or editors of journals, etc. For knowledge to be accepted by the disciplinary community, or for that matter, a project to be executed by members of a discipline, the manuscript or project proposal needs to pass the gatekeepers of that community. All disciplines have a set of either explicit or implicit criteria and rules by which they assess new knowledge or knowledge in the making and make decisions. As 
discussed, these criteria differ among disciplines. These differences might depend on the cognitive or social differences between them.

Cross-disciplinary knowledge configurations, however, are often innovative collaborations between different disciplines, or forms of integration of knowledge originating from within different disciplines. As such, there are is no one reference group, but two or more. The new cross-disciplinary knowledge which is in the making, might be of relevance for more than one disciplinary community. There is no existing set of rules or criteria to evaluate if the new knowledge will be of benefit, or if the project abides to the quality standards of all the different disciplines.

Quantitative indicators might be of some use to assess candidates with regard to their disciplinary peers, but in the case of interdisciplinary project proposals, the disciplinary heterogeneity of the candidate base makes it largely impossible to make use of simple quantitative indicators. As discussed, our knowledge of interdisciplinarity is hardly sufficient to allow for the development of appropriate indicators of interdisciplinary knowledge. But if qualitative nor quantitative evaluation mechanisms are fit to evaluate interdisciplinary research, than what is the alternative?

Grit Laudel (2006) describes peer review processes at two collaborative research networks in Germany (funded by Germany's most important funding agency for university research, the DFG). A network consists of about 10 to 20 research groups from different specialties. The funding programs aim to promote IDR. Although this study is not concerned with social sciences as such, it shows in detail how co-creation of evaluation procedures can be of great value. A review setting is created in which applicants are consulted throughout the review process to ensure interdisciplinary learning of the reviewers. While the project is being developed, this way of organizing the review process allows for the formation of a 'project community' instead of disciplinary community. As Laudel states, however, the applicability of this procedure appears to be limited to areas where 'IDR is common, and where IDR is only moderate'.

The principles addressed by Klein (2008) and discussed in this chapter are less imperative in that they do not put forward a specific way of working, but they are all designed to facilitate a similar cross-disciplinary learning in which a community of scholars and reviewers is formed around a specific interdisciplinary knowledge making endeavor. And by doing so, researchers and reviewers might become more aware of each other's epistemological preferences, disciplinary cultures, other idiosyncrasies. These principles for research assessment developed by Klein should be regarded as an important first step towards more appropriate evaluation procedures for IDR.

\section{CONCLUSION}

In the first part of this chapter, we have presented a brief review of the state of art of bibliometric indicators that are being developed to assess and take stock of IDR. We argue 
that IDR is not so special or unique as one might expect from the descriptions and beliefs found in research policy documents. As stated by sociologists and historians of science, IDR has played a significant role in the development of the sciences since the actual emergence and birth of the disciplines themselves. Therefore, IDR still plays a vital role in research policy and the development of the scientific system as we currently know it. Indicators of IDR, unfortunately, only uncover part of the complex processes of change taking place within the sciences. In this chapter we have therefore argued that we are in need of research into the dynamics of disciplinary growth and change before we can adequately decide what it is we want to measure and indicate about interdisciplinarity before we develop more applied indicators.

In the context of qualitative research assessment (e.g. peer review), we have briefly highlighted three central 'problems' which should be kept in mind when we design evaluation procedures for interdisciplinary research. First, it should be clear from the start that different disciplines and fields have different conceptions of research quality and excellence. This translates to cognitive aspects about what research originality is about, but also socio-structural aspects of the disciplines (cf. supra, section 3.1 and 3.2). What are the preferred communication formats, and what role do citations play in the individual fields.

Emphasizing IDR creates a new boundary within the academy. As Huutoniemi, Klein, Bruun, and Hukkinen (2010) state, "problems become inherent in the creation of distinct criteria and practices for inter- and transdisciplinary evaluation and assessment. To the extent that it would require an operational definition of such research, plus a set of viable parameters to empirically distinguish it from disciplinary research - a problem that has not been solved despite decades long definitional debates". We have pointed out that "the participation of researchers in the definition of criteria and the selection of reviewers ensures that all aspects of the work could be competently assessed. This ongoing dialogue and feedback loops between researchers and reviewers also supports a mutual commitment to long term goals" (Huutoniemi, 2010, p. 313).

As Katri Huutoniemi and Rafols (2017) point out "Although IDR has by definition many characteristics that make it particularly difficult to evaluate, it is important to note that there is also much contingency and variation within disciplinary research. Quality and performance are relative not only to disciplinary standards, but also to the goals, expectations, norms, and values of stakeholders and thus vary from one evaluation context to another". The seven principles for research evaluation proposed by Klein (2008) have therefore been reiterated as an important guideline.

\section{Bibliography}

Abbott, A. (2001). Chaos of disciplines. Chicago: The University of Chicago Press. Abramo, G., D'Angelo, C. A., \& Di Costa, F. (2012). Identifying Interdisciplinarity Through the Disciplinary Classification of Coauthors of Scientific Publications. Journal of the 
American Society for Information Science and Technology, 63(11), 2206-2222. doi:https://doi.org/10.1002/asi.22647

Abramo, G., D'Angelo, C. A., \& Zhang, L. (2018). A comparison of two approaches for measuring interdisciplinary research output: The disciplinary diversity of authors vs the disciplinary diversity of the reference list. Journal of Informetrics, 12(4), 11821193. doi:https://doi.org/10.1016/j.joi.2018.09.001

Bammer, G. (2016). What Constitutes Appropriate Peer Review for Interdisciplinary Research. Palgrave Communications, 2. doi:http://dx.doi.org/10.1057/palcomms.2016.17

Bergmann, M., Brohmann, B., Hoffmann, E., Loibl, C., Rehaag, R., Schramm, E., \& Vos, J. (2005). Quality Criteria of Transdisciplinary Research: A guideline for the fromative evaluation of research projects. Retrieved from Frankfurt am Main:

Science Europe. (2019). Symposium Report: Interdisciplinarity. Retrieved from Brussels, Belgium: http://scieur.org/interdisc-symp

Evans, E. D. (2016). Measuring Interdisciplinarity Using Text. Socius: Sociological Research for a Dynamic World, 2, 1-18. doi:10.1177/2378023116654147--

Gowanlock, M., \& Gazan, R. (2013). Assessing researcher interdisciplinarity: a case study of the University of Hawaii NASA Astrobiology Institute. Scientometrics, 94, 133-161. doi:https://doi.org/10.1007/s11192-012-0765-y

Graff, H. J. (2015). Undisciplining Knowledge: Interdisciplinarity in the Twentieth Century. Baltimore, Maryland: Johns Hopkins University Press.

Guetzkow, J., Lamont, M., \& Mallard, G. (2004). What is Originality in the Humanities and the Social Sciences. American Sociological Review, 69, 190-212.

Heilbron, J. (1990). Het onstaan van de sociologie. Amsterdam: Prometheus.

Huutoniemi, K. (2010). Interdisciplinarity in research evaluation. In R. Frodeman, J. T. Klein, \& C. Mitcham (Eds.), The Oxford Handbook of Interdisciplinarity (pp. 309-320). Oxford, United Kingdom. Oxford University Press.

Huutoniemi, K., Klein, J. T., Bruun, H., \& Hukkinen, J. (2010). Analyzing Interdisciplinarity: Typology and Indicators. Research Policy, 39(1), 79-88. doi:10.1016/j.respol.2009.09.011

Huutoniemi, K., \& Rafols, I. (2017). Interdisciplinarity in Research Evaluation. In R. Frodeman, J. T. A. E. Klein, \& R. C. S. A. E. Pacheco (Eds.), The Oxford Handbook of Interdisciplinarity (Vol. 2nd, pp. 498-512). Oxford, United Kingdom: Oxford University Press.

Jacobs, J. (2013). In defense of disciplines : interdisciplinarity and specialization in the research university. Chicago: The University of Chicago Press.

Klein, J. T. (2004). Guiding questions for integration. In Proceedings of the Integration Symposium 2004. Canberra: Land \& Water Australia; 2005: land\&waterAustralia.

Klein, J. T. (2008). Evaluation of Interdisciplinary and Transdisciplinary Research. American Journal of Preventive Medicine, 38, S116-S123. doi:10.1016/j.amepre.2008.05.010 
Kulczycki, E., Engels, T. C. E., Pölönen, J., Bruun, K., Dušková, M., Guns, R., . . Zuccala, A. (2018). Publication patterns in the social sciences and humanities: Evidence from eight European countries. Scientometrics, 116, 463-486. doi:10.1007/s11192-0182711-0

Lamont, M. (2009). How professors think: Inside the curious world of academic judgement. Cambridge, MA: Harvard University Press.

Lamont, M., \& Guetzkow, J. (2016). How quality is recognized by peer review panels: The case of the humanities. In M. Ochsner \& S. E. Hug (Eds.), Research Assement in the Humanities: Towards Criteria and Procedures (pp. 31-41). Switzerland: Springer, Cham.

Larivière, V., Archambault, E., Gingras, Y., \& Vignola-Gagné, E. (2006). The place of serials in referencing practices: Comparing natural sciences and engineering with social sciences and humanities. Journal of the American Society for Information Science and Technology, 57(8), 997-1004. doi:10.1002/asi.20349

Leydesdorff, L., \& Probst, C. (2009). The delineation of an interdisciplinary specialty in terms of a journal set: The case of communication studies. Journal of the American Society for Information Science and Technology, 60(8), 1710-1718. doi:10.1002/asi.21052

Light, R., \& Adams, J. (2017). A Dynamic, Multidimensional Approach to Knowledge Production. In S. Frickel, M. Albert, \& B. Prainsack (Eds.), Investigating Interdisciplinary Collaboration: Theory and Practice across Disciplines (pp. 127-147). New Brunswick, New Jersey: Rutgers University Press.

Macaluso, B., Pollitt, A., Gunashekar, S., \& Larivière, V. (2015). Comparative Scientometric Assessment of the Results of ERC Funded Projects: Bibliometric assessment report (D5). Retrieved from

Nederhof, A. J. (2006). Bibliometric monitoring of research performance in the Social Sciences and Humanities: A review. Scientometrics, 66(1), 81-100. doi:10.1007/s11192-006-0007-2

Nichols, L. G. (2014). A topic model approach to measuring interdisciplinarity at the National Science Foundation. Scientometrics, 100, 741-754. doi:10.1007/s11192-014-1319-2

Porter, A. L., \& Rafols, I. (2009). Is science becoming more interdisciplinary? Measuring and mapping six research fields over time. Scientometrics, 81(3), 719-745. doi:10.1007/s11192-008-2197-2

Porter, A. L., \& Rossini, F. A. (1985). Peer review of interdisciplinary research proposals. Science, Technology, \& Human Values, 10(3), 33-38.

Schummer, J. (2004). Multidisciplinarity, interdisciplinarity, and patterns of research collaboration in nanoscience and nanotechnology. Scientometrics, 59(3), 425-465. doi:10.1023/B:SCIE.0000018542.71314.38

Stichweh, R. (1992). The Sociology of Scientific Disciplines: On the Genesis and Stability of the Disciplinary Structure of Modern Science. Science in Context, 5(1), 3-15. doi:10.1017/S0269889700001071 
van den Besselaar, P. (2019, 11th April 2019). Interdisciplinary and disciplinary identities: towards a theory of forms of knowledge change. pre-print. BioRxiv.

van den Besselaar, P., \& Heimeriks, G. (2001). Disciplinary, multidisciplinary, interdisciplinary: Concepts and indicators. Paper presented at the International Conference on Scientometrics \& Informetrics, Sydney, Australia.

van den Besselaar, P., \& Heimeriks, G. (2006). Mapping research topics using wordreference co-occurrences: A method and an exploratory case study. Scientometrics, 63(3), 377-393.

van den Besselaar, P., \& Leydesdorff, L. (1996). Mapping change in scientific specialties: A scientometric reconstruction of the development of articial intelligence. Journal of the American Society for Information Science, 47(6), 415-436. doi:10.1002/(SICI)1097-4571(199606)47:6<415::AID-ASI3>3.0.CO;2-Y

Wang, Q., \& Schneider, J. W. (2019). Consistency and validity of interdisciplinarity measures. Quantitative Studies of Science, 1-25. doi:10.1162/qss_a_00011 